\title{
O PAPEL FUNDADOR DAS RELAÇÕES
}

\author{
Maria Joāo Anastácio Centeno*
}

A integração do indivíduo na sociedade processa-se através do uso da linguagem. É ela que permite a transformação do indivíduo biológico em organismo com mente ou self.

A sociedade é caracterizada por indivíduos biológicos que, ao comunicar, participam num acto social. Para pôr em comum conscientemente o self, o indivíduo tem de conhecer a resposta que o seu "gesto" desencadeia no outro. A resposta do outro vai permitir-lhe controlar a sua posterior conduta, orientar a troca neste ou naquele sentido. O feedback é precisamente este método de controlo que reenvia os resultados da acção do indivíduo sobre o outro. Sobrepondo ou interligando os diferentes feedbacks, o indivíduo resolve não só problemas particulares, como também cria hábitos que aplica à solução das classes de problemas. O que acontece é que o indivíduo transcende o que lhe é dado porque através da comunicação descobriu que a sua experiência é partilhada, na medida em que a definição de uma relação entre dois indivíduos depende não só da sequência de acontecimentos que constitui a interacção, mas também da forma como os indivíduos envolvidos vêem e interpretam esses acontecimentos.

Este «mútuo reconhecimento da percepção» faz com que o indivíduo assuma o papel do outro na regulação da sua própria conduta. O homem é essencialmente o animal que assume papéis. Observa constantemente os efeitos da sua acção sobre o outro e usa essa informação para se adaptar à situação. Este processo adaptativo envolve sempre a predição de respostas,

* Escola Superior de Comunicaçāo Social, Lisboa. 
bem como a capacidade que o indivíduo tem de modificar a sua acção quando as previsões estavam erradas.

Ao conseguir desencadear a mesma resposta nele próprio e no outro alcança-se o contexto comum necessário a uma comunidade de significados. A construção do organismo com self envolve, por um lado, a projecção de uma determinada imagem de si, bem como a legitimação dessa imagem projectada, ou seja, o reconhecimento por parte dos outros. $O$ indivíduo vê-se através da propiocepção (as percepções dos seus próprios sentimentos e estados internos) e do reflexo espelhado pelos outros na comunicação interpessoal.

Esta é declaradamente uma leitura interaccional dos fenómenos sociais, em que a interacção é entendida como uma sequência de reacções à qual o organismo com mente consciencializa responde. É necessário considerar não tanto o conteúdo do comportamento, mas a ênfase emocional que o circunscreve num contexto específico. É necessário compreender o comportamento através das relações, na medida em que é o contexto, e particularmente o estado variável da relação entre os indivíduos, que fixa o significado. O que exprimimos, só quando enquadrado numa determinada situação e perante sujeitos concretos, adquire plena significação.

$\mathrm{O}$ que diferencia o indivíduo biológico do organismo com mente é a presença no comportamento de símbolos significativos. Este organismo consegue alcançar um estado de linguagem genuína, hierarquicamente superior a uma comunicação inconsciente ${ }^{1}$; consegue fazer uso dos símbolos, não se limitando a responder a sinais; numa só ideia, adquire uma mente.

A mente traduz-se na internalização do processo social de comunicação em que o significado emerge. É a capacidade que o indivíduo tem de reconhecer a resposta (e os objectos implicados nessa resposta) que o seu próprio "gesto" desencadeia nos outros e ao mesmo tempo de a controlar nestes termos.

Em virtude da internalização do processo social de comunicação, o indivíduo adquire a capacidade de fazer de si próprio um objecto, está consciente de si próprio como um objecto, e de viver num mundo comum, em que a comunicação liga os objectos às pessoas e as pessoas umas às outras.

$O$ indivíduo ao transpor o mundo físico para o mundo da explicação está a assumir os papéis dos objectos que compõem esse mundo, tal como uma criança assume um papel depois de outro. No entanto, para crescer, o indivíduo tem de ter dentro dele toda a actividade organizada, não pode assumir unicamente o papel de um outro específico, tem de assumir o de qualquer outro que participa na actividade comum. E assim generaliza a

1 É importante salientar que a linguagem nāo dispōe de meios para exprimir o que não é consciente. 
atitude de assumir papéis. Na expressão de George Herbert Mead, assumiu o papel do "outro generalizado». Aprendeu a tratar uma determinada classe de contextos, já que qualquer troca entre indivíduos constitui um contexto de aprendizagem e o que pode ser aprendido num determinado momento é limitado ou facilitado pelo que foi previamente aprendido. A aprendizagem é acompanhada por uma mudança na percepção consciente que o indivíduo tem do ambiente que o rodeia. Ela tem as suas raízes imediatas na adaptação exterior, ou seja, na interacção entre o indivíduo e o seu ambiente. $\mathrm{O}$ mundo percebido consiste em duas realidades - uma realidade sensorial, que o indivíduo examina em primeira mão e a realidade normativa ou consensual, que é apreendida dos outros.

A percepção dos indivíduos só actua sobre a diferença. São necessárias, pelo menos, duas entidades relacionadas (reais ou imaginárias) para produzir sinais de diferença, isto é, uma informação nova; de tal forma que a diferença entre elas possa ser imanente à sua relação mútua. A informação que o indivíduo recebe emana de sinais de diferença. A diferença exterior é convertida, através de uma codificação, num acontecimento dentro do sistema de percepção e é precisamente a percepção da diferença que desencadeia a actividade da mente, o agregado de diferenciação de cada um, o que não significa que a diferença seja a causa dessa actividade. A energia que desencadeia a actividade da mente vem de dentro e não do objecto de contemplação; está lá antes da chegada da informação ou do envio da resposta, o que permite ao organismo adiantar-se ao impacto dos acontecimentos.

Ele pode, por exemplo, dar-se conta de não ter recebido uma carta. "Zero", a ausência completa de qualquer acontecimento indicativo, pode, num determinado contexto, ter significado. Por outro lado, as diferenças que, de alguma maneira, não são observadas, não são ideias. As diferenças apresentadas ao de leve e lentamente não são apreensíveis. Não constituem alimento para a percepção.

A diferença está suficientemente afastada do mundo físico, de forma que a mente, que opera com, e com base em, diferenças, trata sempre com elementos intangíveis e tem certas limitações, porque nunca pode chegar à "coisa em si», o Ding an sich kantiano. Ela nunca entra no mundo da explicação, nele só entram diferenças seleccionadas. Da coisa em si só podemos obter informação de uma das suas diferenciações imanentes e susceptíveis de ser reconhecidas pelos órgãos sensoriais. As "coisas» são entendidas como separadas de outras "coisas» e ganham realidade pelas suas relações internas, pelo seu comportamento em relação a outras «coisas» e com o próprio indivíduo. As propriedades dos objectos são função da sua relação com o outro, seja ele um observador ou outro objecto.

No mundo físico, a causa de um acontecimento é constituída por alguma força ou impacto exercido por uma parte sobre outra. No mundo da 
explicação, é necessária uma relação entre duas partes para activar os órgãos sensoriais do receptor.

Considerar a mente separada de impactos e forças reais, confinada a um mundo mais abstracto e derivada da diferença foi um dos factores que conduziram os homens a imaginar a separação entre res cogitans e res extensa. O dualismo cartesiano introduziu um corte entre a capacidade de apreender o processo mental e a atitude de reflectir sobre o mundo natural. A ponte, que só existe em termos analíticos e que separa o espírito da matéria, é ultrapassada pela interactividade do organismo com o ambiente. Estamos a tratar com dois aspectos diferentes do mesmo fenómeno dinâmico da vida. "Se a mente é um sistema de receptores ao longo dos quais podem ser transmitidas as transformações de diferenças, a mente evidentemente não termina na pele, compreende também todos os emissores exteriores à pele que são relevantes para o fenómeno que desejamos explicar»(Bateson, 1991: 223).

$\mathrm{O}$ ambiente tem de ser considerado juntamente com o organismo. Este ao destruir o ambiente está simultaneamente a proceder à sua auto-destruição. Esta consequência põe em evidência o facto de estarmos perante um todo inseparavelmente unido pelas relações, o que faz com que a natureza tenha que ser pensada como uma totalidade sistémica de relações, da qual fazemos parte integrante.

Ao observar a mão ou qualquer outro objecto orgânico atendendo às suas relações e não à coisa em si comprova-se que esse objecto é «quatro vezes» mais bonito do que se imaginava ${ }^{2}$. É de salientar a diferença que existe entre pensar nas coisas e pensar nas relações que existem entre as coisas, entre uma composição de partes que se podem contar e o produto da relação.

Ao representar uma paisagem, um pintor vê-a não como uma árvore, uma casa, uma colina, mas antes como uma forma que tem essa forma. $\mathrm{E}$ as formas estão relacionadas de tal maneira que o artista, enquanto pinta o seu quadro, se esquece de que está a pintar uma colina, uma casa e/ou uma árvore. O mesmo efeito é conseguido quando se examina a mão e se vê um conjunto de relações.

Vivemos num mundo feito unicamente de relações. Elas são «o padrão que liga» todas as coisas vivas, "the pattern which connects». $O$ indivíduo não pode ser considerado como uma entidade separada do ambiente. Ele é

2 Em vez de pensar que temos cinco dedos, deveríamos pensar que temos quatro relações entre dedos: a relação entre um e dois, a relação entre dois e três, entre três e quatro e entre quatro e cinco. Não temos que contar as coisas relacionadas, mas as próprias relaçōes; não temos que contar os relata, mas as relaçōes. 
o resultado da relação com o ambiente e é precisamente o estudo das relações que nos permite compreender a acção do indivíduo.

O meio está no nosso interior e não fora de nós. Os outros fazem parte de nós, somos nós que os transportamos. O mundo físico e o mundo da explicação não estão separados. A Creatura existe no interior e por intermédio do Pleroma; por outro lado, o conhecimento do Pleroma só existe na Creatura. Fora da Creatura nada pode ser conhecido; fora do Pleroma nada há para conhecer. Nós constituimos o lugar de encontro entre estes dois mundos.

O que pensa é um cérebro que está no interior de um homem, que, por sua vez, integra um sistema que compreende o ambiente. Tentar traçar uma linha entre uma parte e o sistema maior ao qual pertence significa criar um componente mitológico chamado «eu».

Existe uma identidade entre a unidade da mente e a unidade da sobrevivência evolucionista. "A ecologia, no seu sentido mais vasto, é entendida como o estudo da interacção e sobrevivência das ideias e programas (isto é, diferenças, complexos de diferenças, etc.) nos circuitos» (Bateson, 1972: 491). O significado de "sobrevivência" torna-se diferente ao deixar de falar da sobrevivência de algo que habita o corpo e começar a pensar na sobrevivência do sistema de ideias no circuito. Os vínculos individuais dos caminhos a que chamamos «eu» já não são tão preciosos, porque esse vínculo é apenas uma parte da mente, entendida num sentido mais lato.

\section{REFERÊNCIAS BIBLIOGRÁFICAS}

Bateson, Gregory (1936) - Naven: a Survey of the Problems suggested by a Composite Picture of the Culture of a New Guinea Tribe drawn from Three Points of View, 2. ${ }^{a}$ ed., Stanford, California, Stanford University Press, 1958.

Bateson, Gregory (1972) - Steps to an Ecology of Mind, 2." ed., Northvale, New Jersey, Jason Aronson Inc., 1987.

Bateson, Gregory (1972a) - Metadiálogos (or. Metalogues), Lisboa, Gradiva, 1989.

Bateson, Gregory (1979) - Natureza e Espírito: Uma Unidade Necessária (or. Mind and Nature), Lisboa, Publicaçōes Dom Quixote, 1987.

Bateson, Gregory/Bateson, Mary Catherine (1987) - El Temor de los Angeles: Epistemologia de lo Sagrado, 2. ed., (or. Angels Fear), Barcelona, Editorial Gedisa, 1994.

BATESon, Gregory (1991) - Una Unidad Sagrada: Pasos Vlteriores hacia una Ecologia de la Mente (or. A Sacred Unity: Further Steps to an Ecology of Mind), Barcelona, Editorial Gedisa, 1993.

BertalanfFy, Ludwig von (1968)-General System Theory: Foundations, Development, Applications, 12. ${ }^{\circ}$ ed., New York, George Braziller, 1995. 
LitTlejohn, Stephen W. (1978) - Fundamentos Tebricos da Comunicação Humana (or. Theories of Human Communication), Rio de Janeiro, Editora Guanabara, 1988.

MEaD, George Herbert (1934) - Mind, Self and Society, Chicago, The University of Chicago Press, 1962.

PAuZE, Robert (1996) - Gregory Bateson, Itinéraire d'un Chercheur, Ramonville Saint-Agne, Éditions Érès.

RIEBER, Robert W. (org.) (1989) - The Individual, Communication, and Society: Essays in Memory of Gregory Bateson, Cambridge, Cambridge University Press.

RUESCH, Jurgen/BATESON, Gregory (1951) - Communication: the Social Matrix of Psychiatry, 3." ed., New York, W. W. Norton \& Company, 1987.

SfEz, Lucien (1993) - Dictionnaire Critique de la Communication: Les Donnés de Base, les Théries Opérationnelles, Tome 1, Paris, Presses Universitaires de France.

Watzlawick, Paul/Beavin, Janet H./JAckson, Don D. (1967)-Pragmática da Comunicaçāo Humana: Um Estudo dos Padrões, Patologias e Paradoxos da Interação, 9. ed., (or. Pragmatics of Human Communication: A Study of Interactional Pattems, Pathologies, and Paradoxes), São Paulo, Editora Cultrix, 1993.

WIENER, Norbert (1950) - Cibernética e Sociedade: O Uso Humano de Seres Humanos, 5. ed., (or. The Human Use of Human Beings), São Paulo, Editora Cultrix, 1978.

WinkIn, Yves (org.) (1981) - La Nouvelle Communication, Paris, Éditions du Seuil.

WinkIN, Yves (org.) (1988) - Bateson: Premier Etat d'un Héritage, Paris, Éditions du Seuil.

WINkIN, Yves (1996) - Anthropologie de la Communication: De la Théorie au Terrain, Bruxelles, De Boeck Université. 